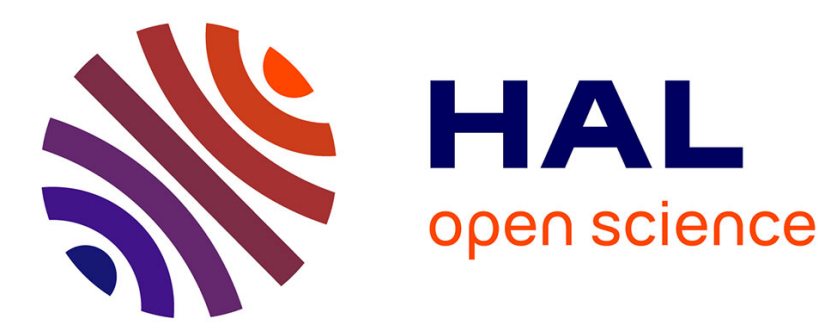

\title{
Investigation of microwave-assisted concrete recycling using single-particle testing
}

Nicholas Lippiatt, Florent Bourgeois

\section{To cite this version:}

Nicholas Lippiatt, Florent Bourgeois. Investigation of microwave-assisted concrete recycling using single-particle testing. Minerals Engineering, 2012, Vol. 31, pp. 71-81. 10.1016/j.mineng.2011.09.017 . hal-00909880

\section{HAL Id: hal-00909880 https://hal.science/hal-00909880}

Submitted on 27 Nov 2013

HAL is a multi-disciplinary open access archive for the deposit and dissemination of scientific research documents, whether they are published or not. The documents may come from teaching and research institutions in France or abroad, or from public or private research centers.
L'archive ouverte pluridisciplinaire HAL, est destinée au dépôt et à la diffusion de documents scientifiques de niveau recherche, publiés ou non, émanant des établissements d'enseignement et de recherche français ou étrangers, des laboratoires publics ou privés. 




Open Archive Toulouse Archive Ouverte (OATAO)

OATAO is an open access repository that collects the work of Toulouse researchers and makes it freely available over the web where possible.

This is an publisher-deposited version published in: http://oatao.univ-toulouse.fr/ Eprints ID: 5105

To link to this article: DOI:10.1016/j.mineng.2011.09.017

http://dx.doi.org/10.1016/j.mineng.2011.09.017

\section{To cite this version:}

Lippiatt, Nicholas and Bourgeois, Florent Investigation of microwave-assisted concrete recycling using single-particle testing. (2012) Minerals

Engineering, Vol. 31. pp.71-81. ISSN 0892-6875

Any correspondence concerning this service should be sent to the repository administrator: staff-oatao@inp-toulouse.fr 


\title{
Investigation of microwave-assisted concrete recycling using single-particle testing
}

\author{
Nicholas Lippiatt*, Florent Bourgeois \\ Université de Toulouse, INPT, UPS, LGC (Laboratoire de Génie Chimique), 4 allée Emile Monso, BP 44362, 31432 Toulouse Cedex 4, France
}

\begin{abstract}
A B S T R A C T
Microwave heating stands as a strong candidate for selective liberation of multiphase materials like concrete. It takes advantage of the differences in thermal, dielectric and mechanical properties of each of the components to create stress gradients that can lead to grain boundary fracture and embrittlement.

The work and results reported are concerned with selective liberation of concrete's raw constituents for recycling by combination of microwave heating and comminution. A single particle testing approach is presented for detailed analysis of the process. Concrete particles $10 \mathrm{~mm}$ in size are treated individually in a single mode cavity microwave $(2.45 \mathrm{GHz}, 2 \mathrm{~kW})$ test apparatus. The microwave induced effects are quantified by single particle impact testing on a fast Hopkinson bar. Analysis of impact traces reveals a thorough embrittlement of concrete particles from microwave treatment and fragment analysis confirms the potential of microwaves for selective liberation of the raw constituents of concrete. These results validate that microwaves and comminution can be combined to liberate concrete's raw constituents.
\end{abstract}

Keywords:

Concrete

Recycling

Comminution

Liberation

\section{Introduction}

More natural resources are consumed for the production of concrete than for any other product (Nawy, 2008). For new concrete structures requiring standard performance levels, the use of recycled concrete aggregate (RCA) is generally accepted to be limited to $20-30 \%$ of total aggregate volume (Tam and Tam, 2006) however for Europe this number is much lower. Of 21 countries listed by the European Aggregates Association, 18 source less than 10\% of total aggregate from recycled material (Klee, 2009). Promising results have been obtained with $60 \%$ recycled concrete aggregate volume fraction in some applications (Soutsos et al., 2010) though going beyond these limits produces a significant decrease in concrete strength (Malesev et al., 2010; Tam et al., 2007). Recycling of construction waste, of which concrete is a major component, is over 50\% for many European countries (Fischer and Davidsen, 2010) but this is largely backfill operations for which many other materials with much less added value are also suitable, so could be considered a waste. It also means a significant proportion of material is ending in landfill that could easily be recycled. One key reason is that RCA particles produced by conventional means contain too high a cement to aggregate ratio, the presence of cement being the cause of the adverse effect of RCA on concrete properties. Reducing the amount of cement in RCA is an important area of research and development (Tam et al., 2007).

\footnotetext{
* Corresponding author. Tel.: +33 05343236 33; fax: +33 0534323700 .

E-mail addresses: nicholasrichard.lippiatt@inp-toulouse.fr (N. Lippiatt), florent. bourgeois@inp-toulouse.fr (F. Bourgeois).
}

The mechanical performance of concrete with $30 \%$ of coarse aggregate replaced with RCA is almost identical to concrete with $100 \%$ of coarse aggregate replaced with treated RCA, when the RCA has been treated so as reduce mortar content by $30 \%$ (Akbarnezhad et al., 2011). However, the mortar content bears no direct relationship with the degree of liberation of aggregates, which is likely to be the most important factor determining the recycling potential of RCA. Indeed, it appears to be the interaction of surfaces during cement curing that determines the disparity in mechanical performance of concrete made with RCA or natural aggregate (NA). In the extreme, the reduction of mortar content could be near $100 \%$ but if the remaining mortar was spread evenly over the surface of aggregate, the liberation value would be zero and the mechanical performance of concrete made with such RCA would be poor. The fragmentation method, which should promote fracturing along the aggregate-cement interface, is therefore pivotal to the issue of concrete and RCA recycling, and justifies the focus on microwave induced fracture as an alternative to current mechanical methods used for producing RCA.

To the best of the authors' knowledge, the level of aggregate liberation required so that RCA can replace NA in concrete is unknown. The values above were achieved using similar processes and materials to those of this work and therefore are assumed to rely on the same fracture pattern, therefore $30 \%$ is likely a good target until more information is available. What this means in terms of liberation though is dependant on the original ratio of concrete to cement. This problem of finding a necessary liberation fraction is related to the more generic question of selective liberation with multiphase materials. 
Another important factor to consider is that if cement and aggregate are separated then both can be reused in their original manner, as concrete components. Cement can be made from as much as $100 \%$ recycled material and still have acceptable mechanical performance (Galbenis and Tsimas, 2006; Costes et al., 2010). The production of cement uses more energy and releases more carbon dioxide than any other part of the concrete production process, thus cement recycling is likely to have a large environmental impact, possibly even larger than recycling aggregate.

Microwave technology has long been recognised as one possible solution for achieving selective liberation of multiphase materials, with beneficiation of mineral ores receiving significant attention. Microwave treatment has been shown to increase the metal recovery from copper (Vorster et al., 2001) and gold (Amankwah and Ofori-Sarpong, 2011) ores. Similarly, significant reduction in strength and improvement in grindability have also been obtained with coal (Marland et al., 1998) and iron ores (Kumar et al., 2010).

Even more so than mineral ores, concrete is a multiphase material, hence microwaves are expected to be effective for fracturing concrete. Indeed, it contains particulate phases (aggregate and sand particles) embedded in a continuous phase (cement paste), which includes water containing pores. The cement matrix creates additional complications to a theoretical understanding of the interaction between microwaves and concrete because of its multiphase and multiscale nature (Lee et al., 2009; Constantinides and Ulm, 2004). It bears many distinct mineral phases in itself (Lee et al., 2009) whose concentrations vary throughout the bulk of the cement phase, particularly at the interface of aggregate and cement. Pores are also not homogeneously distributed throughout cured cement, and porosity is highest near the interface of aggregate and cement interface (Roy et al., 1993). A valuable understanding of the interaction between microwaves and cement would be gained by measuring and comparing relevant properties for all the phases present. When dealing with microwave heating, which affects concrete from multiple sources from within the material itself, the presence of heterogeneities at small scales inside the cement matrix likely plays a pivotal role on the interactions between microwaves and concrete. It seems that these interactions would require a multiscale analysis of the dielectric and thermal properties of concrete, in very much a similar way to that done by Constantinides and Ulm (2004) who investigated local mechanical properties of concrete by micro-indentation and micro-mechanical modelling. One area of particular interest is the $10-20 \mu \mathrm{m}$ thick interfacial transition zone (ITZ) around aggregate particles, with higher porosity and lower mechanical strength than the bulk of the cement paste (Scrivener et al., 2004) that must play a major role in the fracture and liberation behaviour of concrete.

The complex, multiscale and multiphase nature of cement and the effect that this has on the interaction between concrete and microwaves is difficult to describe in general terms as the spatial distribution of different phases and water through cement is likely to be the most important factor in the distribution of power density and fracture growth given the highly localised nature of microwave-material interaction. In particular, the behaviour of water during microwave heating of concrete, which gives rise to both heat and stress sources, is without doubt the most important and complex issue in the process investigated. Recognition that the localised nature of the microwave-concrete interaction is of paramount importance because of the textural complexity of cured cement raises issues about the relevance of using average properties, such as mean power density or loss constant for cured cement, for describing and analysing microwave-concrete interactions. In depth analysis of cement at very fine levels would add valuable understanding to the interaction between microwaves and concrete but at this early stage it is probably enough to recognise that water is the controlling phase and focus on a simpler macroscopic approach.

Average properties of concrete phases are listed in Table 1. It is the differences in these properties that make it possible to separate these phases with rapid microwave heating. The values are average for the bulk at $20^{\circ} \mathrm{C}$ and exposed to $2.45 \mathrm{GHz}$ microwaves making them applicable only to the initial stages of heating. This discontinuity of properties is what leads to stress and fracture formation in concrete during rapid microwave heating.

From Table 1, aggregate and cement phases exhibit differences in thermal properties, which are favourable for phase boundary fracture and separation during rapid heating (Vorster et al., 2001). Indeed, extensive simulations of microwave heating of mineral ores have highlighted the importance of specific heat and coefficient of thermal expansion (Ali, 2010). Density is also important as the heating is volumetric. Heating rate is proportional to the applied power density $\mathrm{W} / \mathrm{m}^{3}$ and a change in temperature leads to a change in volume, which in turn generates internal stresses. This is good for the separation of aggregate and cement as the difference in thermal expansion can be $50-300 \%$. The importance of thermal conductivity decreases the shorter that microwave exposure times become. So, ignoring conduction, assuming equal heat flux, including density and specific heat for volumetric heating, the difference in heating rates between aggregate and cement could be as much as $20 \%$. From these numbers water will heat 4-60 times faster than the other concrete phases. Ignoring conduction this means initial expansion of water will be 150-2000 times the other concrete phases.

Already, a convincing body of evidence indicates the high potential of microwaves for selective fracture and liberation of concrete, from the early work by Figg (1974) who observed a reduction in concrete strength and increase in the ease of separation of cement and aggregate phases when concrete is exposed to lower power microwaves, to the more recent work on improved beneficiation of recycled concrete aggregates using microwaves by Akbarnezhad et al. (2011). It is worth emphasising that microwaves induce stresses from multiple sources located within the particle. This is in contrast with standard comminution techniques that apply stresses through few external contact loads and the reason microwave based comminution techniques are deemed to have such potential. Using purely physical means, namely through a series of high velocity impacts, Tomas et al. (2000) achieved an aggregate liberation grade of approximately $50 \%$ with specific energy consumption of 5.5-9.5 $\mathrm{kWh} / \mathrm{t}$, depending on the fragment size under consideration. Fracture behaviour favours the liberation of aggregate from cement due to the higher strength and stiffness of aggregate compared to cement (see Table 1).

This work presents a single-particle testing approach for studying the possibility of combining microwaves and physical comminution for recycling concrete, the goal being to produce material that can be reused as the raw constituents of concrete. This is clearly a technical challenge, but if selective liberation of aggregate and cement could be harnessed efficiently then the recycling of concrete would not be restricted to downcycling operations like backfilling or as RCA with the aforementioned limitations, arguably neither of which is an efficient recycling option for such a high impact and added value product. The single-particle test work combines a single-mode cavity microwave test rig and a fast Hopkinson bar.

Fig. 1 presents the concrete recycling process rationale, which uses a combination of microwave-induced embrittlement followed by physical comminution and/or separation, and the translation to single-particle experimental testing and characterisation.

The justification for applying a single-particle approach to microwave-assisted embrittlement and recycling of concrete is that it permits breaking the process into its most elementary steps. 
Table 1

Typical properties of aggregates and cement found in the literature.

\begin{tabular}{|c|c|c|c|c|c|c|c|}
\hline $\begin{array}{l}\text { Concrete } \\
\text { phases }\end{array}$ & $\begin{array}{l}\text { Relative dielectric } \\
\text { constant }\end{array}$ & $\begin{array}{l}\text { Loss } \\
\text { factor }\end{array}$ & $\begin{array}{l}\text { Expansion coefficient } \\
\left(\mu \mathrm{m} /{ }^{\circ} \mathrm{C}\right)\end{array}$ & $\begin{array}{l}\text { Specific heat } \\
\left(\mathrm{J} / \mathrm{kg}^{\circ} \mathrm{C}\right)\end{array}$ & $\begin{array}{l}\text { Modulus of } \\
\text { elasticity (GPa) }\end{array}$ & $\begin{array}{l}\text { Compressive } \\
\text { strength (MPa) }\end{array}$ & $\begin{array}{l}\text { Density } \\
\left(\mathrm{kg} / \mathrm{m}^{3}\right)\end{array}$ \\
\hline Aggregate & $3-15^{\text {b,e,f,g,i,k }}$ & $0.08-0.2^{\mathrm{e}, \mathrm{i}, \mathrm{k}}$ & $6-13^{\mathrm{a}, \mathrm{b}, \mathrm{c}}$ & $740-920^{\mathrm{a}, \mathrm{b}, \mathrm{d}}$ & $50^{\mathrm{a}, \mathrm{b}}$ & $60-130^{\mathrm{a}}$ & $2320-2700^{j}$ \\
\hline Cement & $5.3-10^{\mathrm{b}, \mathrm{h}, \mathrm{i}}$ & $0.48^{\mathrm{i}}$ & $18-20^{\mathrm{b}, \mathrm{c}}$ & $1550-1600^{\mathrm{a}, \mathrm{b}}$ & $25^{\mathrm{a}, \mathrm{b}}$ & $21^{\mathrm{a}}$ & $1290-1540^{\mathrm{j}}$ \\
\hline Water & $80^{\mathrm{a}, \mathrm{k}}$ & $12^{\mathrm{k}}$ & $210^{\mathrm{a}}$ & $4200^{a}$ & - & - & $1000^{\mathrm{a}}$ \\
\hline
\end{tabular}

a Engineeringtoolbox.com.

b Akbarnezhad et al. (2011).

c Youtcheff (2011).

d Schärli and Rybach (2001).

e Ulaby et al. (1990).

${ }^{\mathrm{f}}$ Martinez and Byrnes (2001).

g Knight and Abad (1995).

h Pokkuluri (1998).

${ }^{\mathrm{i}}$ IMS.

j Walker (2011).

k Metaxas and Meredith (1988).

Process rationale

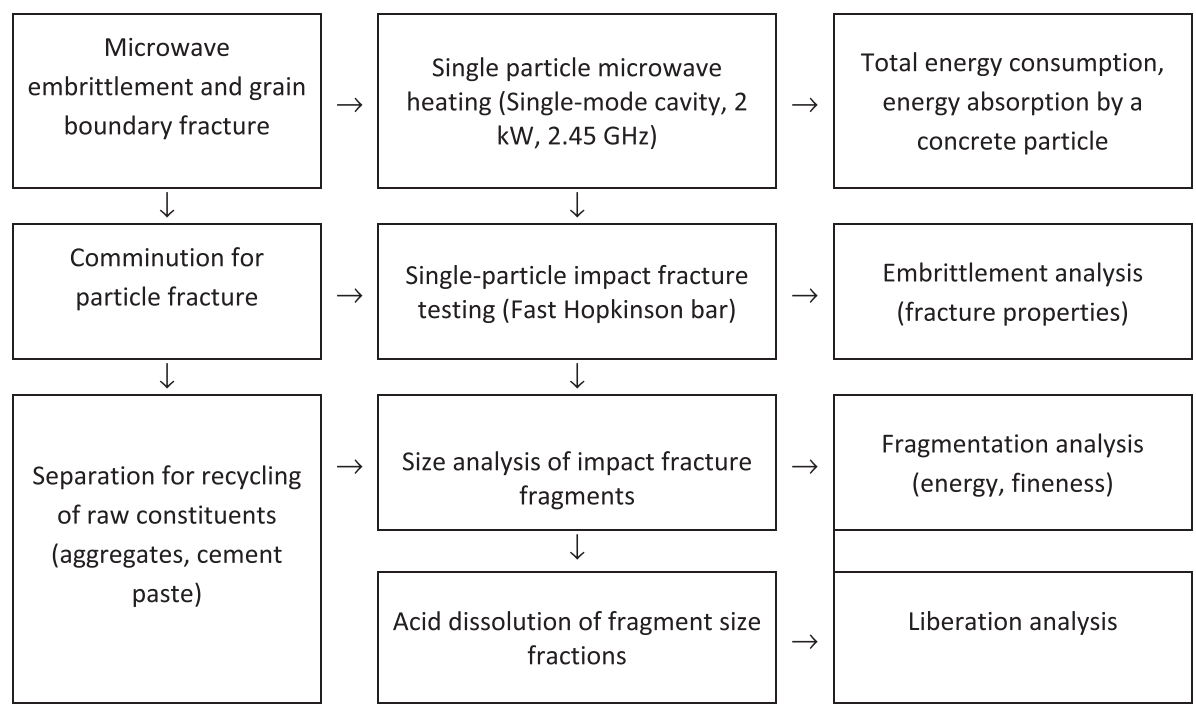

Fig. 1. Concrete recycling rationale and corresponding single particle testing and analysis approach.

In principle, this approach allows changes in material properties and energy consumption to be tracked at every step, thereby giving a firm basis for understanding, improving and developing an industrial process. In the present work, single-particle tests and analyses are presented in detail.

\section{Materials and methods}

\subsection{Concrete samples}

The end objective of this work is to produce high purity cement, aggregate and sand concentrates from demolition concrete, thereby achieving complete concrete recyclability. In order to develop an understanding of the mechanisms at play, concrete particles were produced under controlled conditions using CEM 152.5 Portland cement. This is a high quality and versatile cement that has been used for many years and complies with the European standard SN EN 197-1, containing at least 95\% fine ground Portland clinker. The concrete was prepared with a water-to-cement ratio $(\mathrm{w} / \mathrm{c})$ of 0.6 , which yields complete hydration of the cement. The aggregate-to-cement ratio $(\mathrm{A} / \mathrm{C})$ used was $2.6 \%$, or $72 \%$ aggregate by mass on a dry basis, a common value for standard applications.
After curing it was confirmed by dissolution of the cement phase that the aggregate phase constituted approximately $60 \%$ of the concrete mass, which is close to the $62 \%$ mass fraction used in the original mix. The concrete was cast in $100 \mathrm{~mm}$ thick slabs, allowed to cure for 28 days in water then cut into $10 \times 10 \times 100 \mathrm{~mm}$ rods. These were stored for seven months before being cut using a Buehler HC 15 diamond blade into approximately $10 \mathrm{~mm}$ cubes for single-particle testing.

The concrete was prepared using siliceous NA with particle size in the range $2-2.5 \mathrm{~mm}$. Naturally, the size distribution of aggregate in the cubic particles differed slightly from the original one as some aggregates were sectioned during block cutting. The aggregate size distribution after cutting was measured by selective dissolution of the cement paste and it is this that is presented as the aggregate size distribution. The cement dissolution protocol is discussed later in this article.

\subsection{Experimental set-up}

The two pillars of the experimental program designed to explore the proposed concrete recycling scheme are a $2 \mathrm{~kW} /$ $2.45 \mathrm{GHz}$ single-mode microwave test rig from SAIREM (www.sai- 
rem.com) and a fast Hopkinson bar. The former is used to subject concrete particles to microwaves, whereas the latter is used to both impact fracture the concrete particles and access their fracture behaviour. A $2.45 \mathrm{GHz}$ microwave test rig was chosen as free water exhibits a higher loss factor at this frequency than at $915 \mathrm{MHz}$, the other standard industrial microwave frequency and so the concrete should heat faster.

The microwave test rig (see Fig. 2) comprises an $86 \times 43 \mathrm{~mm}$ rectangular wave guide and a single-mode sample cavity. The cavity is designed to hold a $30 \mathrm{~mm}$ diameter silica (microwave-transparent) tube holder inside which concrete particles are placed for testing. In the tests reported here, one single concrete particle is placed inside the sample tube. The test rig allows the microwave power applied to particles to be adjusted so as to produce a continuous standing wave with an intensity of up to $2 \mathrm{~kW}$. Also included in the microwave rig are a timer to control exposure time and a reflected power detector that records the instantaneous energy absorbed during a test.

The comminution properties of individual concrete particles, whether untreated or treated with microwaves, are tested using a short vertical Hopkinson bar, the essential features of which can be found in Bourgeois and Banini (2002). The rod used here is made of $43 \mathrm{CrMo} 4$ steel with length $1.5 \mathrm{~m}$ and diameter $20 \mathrm{~mm}$. The compression wave is measured using a full Wheatstone bridge with $540 \Omega$ semi-conductor strain gages from Micron Instruments with a gage factor of 140 . Bridge balancing and conditioning is achieved with an MGCPlus system from HBM. The $0-10 \mathrm{~V}$ signal output by the ML10B amplifier is sampled and digitised at a rate of $1 \mathrm{MHz}$ using a Spectrum PCI Express data acquisition card. Overall, the experimental set-up is a highly sensitive measurement system, which allows precise measurement of the force applied to, and energy absorbed by the particle during a dynamic impact.

The value of the Hopkinson bar testing apparatus is twofold. Firstly, analysis of the output signal yields the total energy absorbed by the particle during the impact and, under favourable conditions, gives indicators of a particle's degree of embrittlement through measurement of fracture-sensitive properties such as energy-atfirst-fracture, particle strength and toughness. Secondly, since the impact of a single particle can be considered as an elementary comminution event, analysis of the post-impact fragment size distribution and liberation gives us direct insights into the comminution/ liberation/energy relationship for the particles under study.

\subsection{Post-treatment data analysis}

The main issue with concrete recycling is one of energy consumption. As indicated earlier, the energy absorbed by the particle during impact testing, whether microwave-treated or untreated can be quantified precisely using the Hopkinson bar. Measurement of the energy absorbed by single particles during microwave tests is not so straightforward unfortunately. The microwave test rig used in this work is an open system, as shown in Fig. 2, so that energy absorbed by a single concrete particle during exposure to microwaves is lost to the particle's surroundings through water vapour losses and heat exchange with the air. Temperature measurements of the particle surface, given the small size of the particles tested in this work, could be used to estimate the average particle temperature, hence the energy absorbed during exposure to microwaves. In this work mean particle temperature was estimated by combining measurements of mass loss during microwave tests and thermo-gravimetric analysis (TGA) mass loss curves. Combining the energy absorbed during impact testing and estimates of absorbed microwave energy gave a value for total specific energy consumption.

The size reduction and liberation analysis is the other side of the problem that needs to be quantified. Size reduction is measured by dry sieving the product of the single-particle Hopkinson bar tests through a series of narrow sieve fractions. Strictly speaking, liberation can only be measured by electron microscopy and image analysis, using highly dedicated equipment such as the MLA (Gu, 2003) or the QEMSCAN (Gottlieb et al., 2000). In this study, for budgetary and time constraints, liberation is quantified with a simple technique that takes advantage of the material being made of phases with different chemical activity. Individual size fractions produced by the first sieving step is dissolved separately using $25 \mathrm{ml}$ of a $2 \mathrm{M}$ hydrochloric acid solution per gram of concrete. This is done at room temperature in a glass beaker with a magnetic stirrer rotating at $300 \mathrm{rpm}$. Sufficient time is allowed for all the cement to dissolve, which varies between $20 \mathrm{~min}$ for small fragments to $2 \mathrm{~h}$ with $>5 \mathrm{~mm}$ concrete fragments. At any rate, calibration tests were carried out to prove that the siliceous aggregates did not dissolve significantly under such conditions. Once a size fraction has been dissolved, it is re-sieved. Aggregate liberation in that size fraction is calculated by comparing the mass of aggregates in the size fraction before and after dissolution, with the assumption that the aggregates that stay in the size fraction before and after dissolution were liberated. The technique and corresponding liberation calculation formulae can be found in Kiss and Schönert (1980).

\section{Results and analysis}

\subsection{Single-particle microwave testing and analysis}

As per Fig. 1, the single-particle testing process starts with subjecting the particle to microwave heating. Due to the interrelationship between electric field, the input power of the microwave

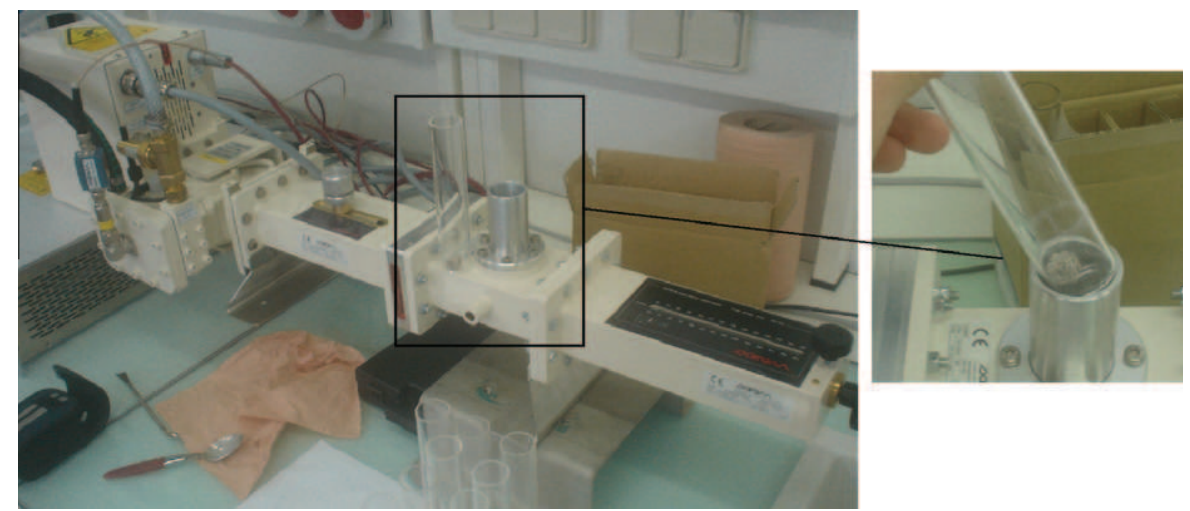

Fig. 2. Left: single-mode cavity microwave test apparatus from SAIREM (www.sairem.com); Right: sample holder with a $10 \mathrm{~mm}$ concrete particle. 
system and the sample, optimum settings for the iris and short-circuit piston were found manually using a typical sample before treating test samples. Once these conditions were determined, they were used with all the single-particle tests, so that all samples would receive as near as possible to maximum and equal amounts of energy. Samples were treated for 10,30 or $50 \mathrm{~s}$ or left untreated.

Both the input and reflected power during a single particle microwave test are measured at a sampling rate of $1 \mathrm{kHz}$ during a single-particle microwave test. They are recorded as a $0-10 \mathrm{~V}$ analogue signal, whose range corresponds to the $0-2000 \mathrm{~W}$ power input range of the microwave system. The measured raw voltages are filtered in two steps, first using a Fast Fourier Transform with a $50 \mathrm{~Hz}$ cut-off frequency, then with a simple moving average of width 100 points or $0.1 \mathrm{~s}$. The actual power absorbed by the system during the test is then calculated by difference between the smoothed input power and reflected power signals. Fig. 3 shows one example of input, reflected and absorbed power signals, for a $10 \mathrm{~mm}$ concrete particle with a mass of $2.10 \mathrm{~g}$ exposed to a power input of $1900 \mathrm{~W}$ or $95 \%$ of the system's nominal power input for $43 \mathrm{~s}$. It can be seen that this system reaches the set power level in approximately $3 \mathrm{~s}$.

The energy absorbed by the system during a microwave test is calculated by integration of the power signal. In the case of Fig. 3, we find that the integral of the power input yields $81.3 \mathrm{~kJ}$. This value is just under the nominal power input, $1900 \mathrm{~W} \times 43 \mathrm{~s}=81.7 \mathrm{~kJ}$, as the power input takes a few seconds to reach its nominal $1900 \mathrm{~W}$ setting. In this case, the system absorbed $18.4 \mathrm{~kJ}$ or $22.6 \%$ of the power input. This value is typical of all the tests that were carried out, for which it never seemed possible to input more than $20-25 \%$ of the input power into the system.

\subsection{Estimation of absorbed microwave energy by TGA}

As discussed earlier, the microwave system used here is an open system, so that the value of the energy absorbed does not correspond to the energy really absorbed by the particle.

Estimation of the energy absorbed by a single particle during a microwave test is inferred from thermogravimetric analysis (TGA) of the cured cement paste, performed using a TA Instruments Q600 thermal analyzer. Cement was mixed and cured in exactly the same way as the concrete but using no aggregate, then cut to yield $10 \mathrm{~mm}$ cement cubic particles. Cement particles were subjected to microwaves using the exact same method as the concrete treated for $50 \mathrm{~s}$, such that TGA curve could be measured for both untreated and microwave treated cement samples. The TGA curves, shown in Fig. 4 are almost parallel from approximately $160^{\circ} \mathrm{C}$ onwards. From this it is concluded that the temperature of the treated cement reached $160^{\circ} \mathrm{C}$ during microwave exposure. The difference in mass lost between untreated and treated cement, 9.3\% in this case, is due to be water loss only. Indeed, the temperature did not reach the $425-500{ }^{\circ} \mathrm{C}$ temperature range at which portlandite decomposes (Lee et al., 2009), which is further confirmed by the fact that the same mass loss is obtained in this temperature region in both cases. This mass loss, which equals $5 \mathrm{wt} \%$, gives the amount of portlandite in the cement. The small hump that is seen around $700{ }^{\circ} \mathrm{C}$ corresponds to the decomposition of calcium carbonates.

Accounting for the $62 \mathrm{wt} \%$ aggregate in the concrete, the TGA curve for the cement phase was converted to a TGA curve for the concrete as a whole, which is shown in Fig. 5. The mean temperature reached by microwave samples was estimated by assuming that the cement in concrete loses the same mass fraction of material at the same temperature as pure cement phase under TGA analysis and no mass is lost from the aggregate during TGA or microwave treatment. The mean mass lost from concrete treated for 10,30 and $50 \mathrm{~s}$ is $0.6 \%, 6 \%$ and $7 \%$ respectively. From the adjusted TGA curve this corresponds to a temperature of $52{ }^{\circ} \mathrm{C}$, $125^{\circ} \mathrm{C}$ and $160^{\circ} \mathrm{C}$, Fig. 6 . From the TGA curve and supported by the $10 \mathrm{wt} \%$ water used in the original concrete mix this would seem to confirm that all mass lost during microwave heating was water and the temperature of portlandite degradation, approximately $400{ }^{\circ} \mathrm{C}$, was not reached. There was visual confirmation in all single particle microwave tests that a significant amount of water was released, some of which would condense on the upper part of the silica sample holder (see Fig. 2).

An alternate technique would have consisted in analysing the whole concrete by TGA. Given that TGA requires only $50 \mathrm{mg}$ of material, this would have meant a very fine grinding of the concrete prior to TGA analysis, to ensure a representative concrete sample. Analysis of pure cement is simple and was deemed suitable for analysis by TGA as aggregate does not show any measurable mass loss until very high temperatures.

A first approximation of microwave energy absorbed by the sample was determined from the known fractions of aggregate to cement, typical values of specific heat from Table $1,830 \mathrm{~J} \mathrm{~kg}^{-1}{ }^{\circ} \mathrm{C}^{-1}$ for aggregate and $1550 \mathrm{~J} \mathrm{~kg}^{-1}{ }^{\circ} \mathrm{C}^{-1}$ for aggregate and the enthalpy of evaporation of water and the mass lost during microwave treatment. For $10 \mathrm{~s}, 30 \mathrm{~s}$ and $50 \mathrm{~s}$ this equals 14,70 and $87 \mathrm{kWh} / \mathrm{t}$ of microwave energy, approximately $4 \%$ of the energy absorbed by

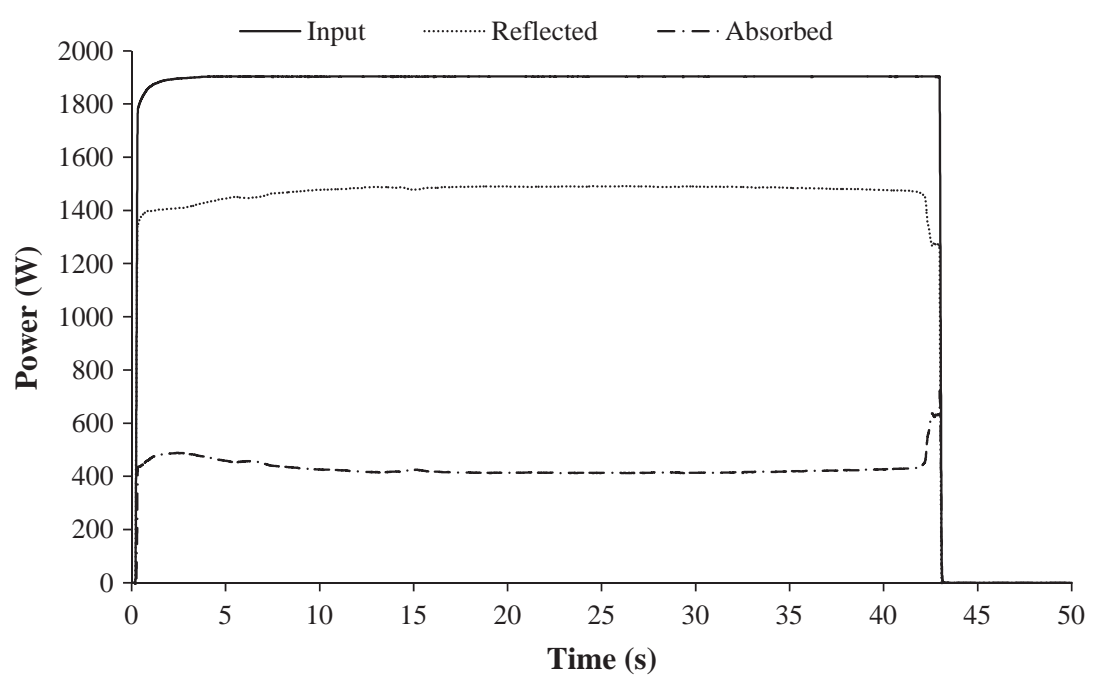

Fig. 3. Example of processed microwave power measurement for a single particle microwave test. 


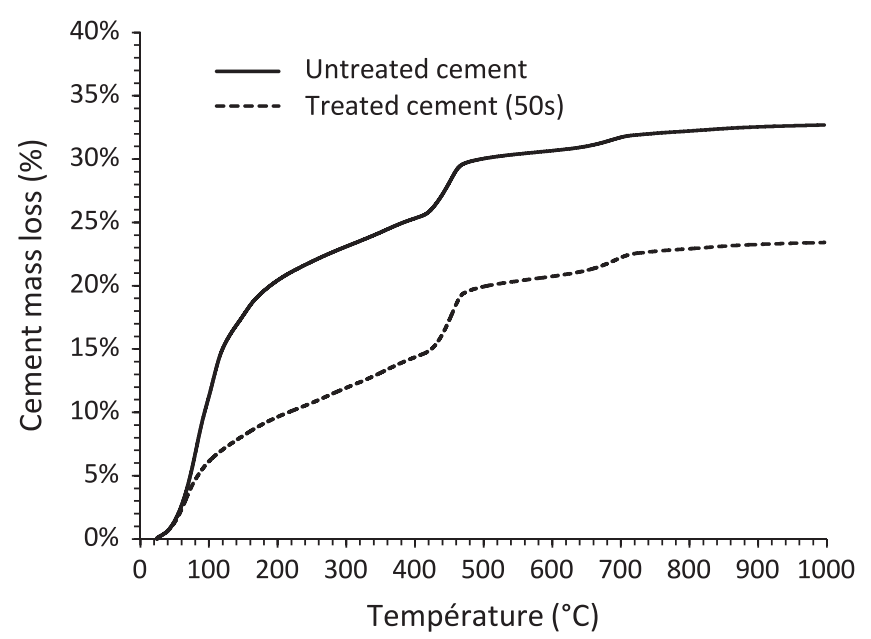

Fig. 4. TGA curve for cured cement, untreated and microwave treated for $50 \mathrm{~s}$.

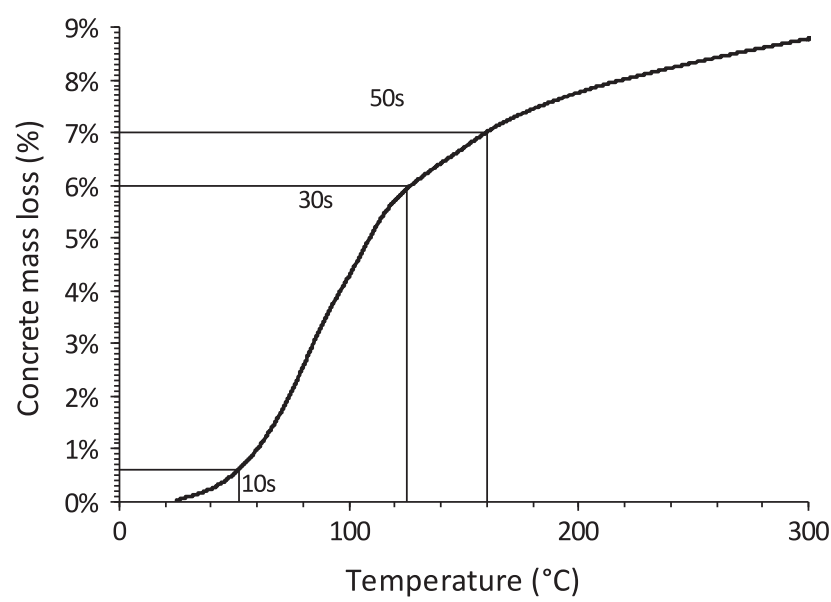

Fig. 5. TGA curve for concrete, showing measured mass loss and maximum temperature estimations for $10 \mathrm{~s}, 30 \mathrm{~s}$ and $50 \mathrm{~s}$ microwave exposure.

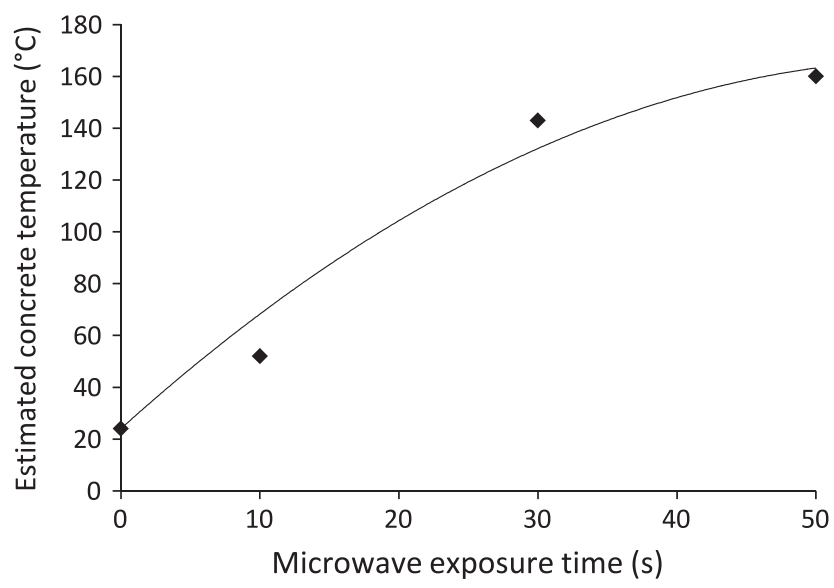

Fig. 6. Estimated temperature of single concrete particles as a function of microwave exposure time.

the system. These values are 1 to 2 orders of magnitude higher than the $1-3 \mathrm{kWh} / \mathrm{t}$ reported in the literature with ores (Ali and Bradshaw, 2009). Notwithstanding the errors in the above calculations, the energy values seem reasonable. Indeed, when considering that the electric field applied here is only one tenth that used by Ali and Bradshaw with a $30 \mathrm{~kW}$ generator and exposure times of a few milliseconds only, recalling that heating rate, the key factor in stress formation, is proportional to the square of the electric field strength, it is not surprising to obtain higher mass specific energy consumption.

As some concrete samples were observed to glow and others showed evidence of melting, burning and spalling it is probable that local temperatures were significantly in excess of the average maximum temperatures ascertained from the TGA curve.

\subsection{Single-particle impact fracture testing}

Single-particle Hopkinson bar testing yields impact size reduction and liberation data by analysis of the fragments produced after impact, along with measurement of the level of damage of a concrete particle, before and after microwave treatment. Fig. 7 shows typical impact traces measured with the fast Hopkinson bar for untreated and microwave-treated $10 \mathrm{~mm}$ concrete particles, using a $40 \mathrm{~mm}$ bearing ball dropped from $100 \mathrm{~mm}$. For sake of comparison, all impact tests reported here were carried out using the same impact conditions. Of the whole trace, only the first $500 \mu$ s are shown here in order to emphasise the particle's compression phase during which visible fracture events may occur, yielding measurements of energy-at-first-fracture and particle strength.

Under the conditions of the impact test, the untreated concrete particle exhibits a Hopkinson bar impact behaviour that is typical of elastic brittle materials, showing a rapid linear force rise that leads to a sharp first fracture event. The particle in this case first fractured at a force of $768 \mathrm{~N}$, after having absorbed $7.1 \mathrm{~mJ}$, giving a specific fracture energy of $3.6 \mathrm{~mJ} / \mathrm{g}$ and particle strength of $7.7 \mathrm{MPa}$.

The gradual change in mechanical behaviour with exposure time is best seen when zooming on the first $20 \mu \mathrm{s}$, as shown in Fig. 8. Indeed, we see a monotonic decrease in the slope of the force rise during the compression before the first fracture event, which is a direct measure of the reduction in stiffness (alt. increase in damage) of the concrete particles with exposure time.

Under the impacts conditions used, which were kept the same for all concrete samples in order to compare their subsequent fragment size distribution and liberation, the Hopkinson bar signal does not reveal any identifiable fracture event for the particle treated for $50 \mathrm{~s}$ (see Fig. 7). Particles have undergone such a high level of damage that it no longer behaves like an elastic-brittle material. The mechanical behaviour of microwave treated concrete particles is particularly interesting. Impact tests with very low amounts of energy were carried out to assess whether some residual elasticbrittle behaviour could be detected with microwave particles treated for $50 \mathrm{~s}$. On rare occasions only did microwave treated particles exhibit any visible fracture event; hence it is difficult to measure fracture energy or particle strength with the Hopkinson bar test for particles treated under such conditions. For this reason the maximum force experienced by the concrete particles during an impact is used as a direct indicator of the mechanical strength.

Fig. 9 and Table 2 give measurements obtained from analysis of Hopkinson bar tests that quantify the change of embrittlement between untreated and treated concrete particles. Fig. 9 was included here to give the reader some idea about the measured variability from one concrete particle to the next. All this quantitative data demonstrate that microwave treatment was able to alter concrete particles in a profound way, with all reported properties being reduced by a factor of 3 or more.

It is noted that particle strength values reported here, which are calculated using an approximation proposed by Tavares and King (1998) for single-particle impact test analysis cannot be compared with standard values of stiffness reported for concrete. The values can however be compared in relative terms. 


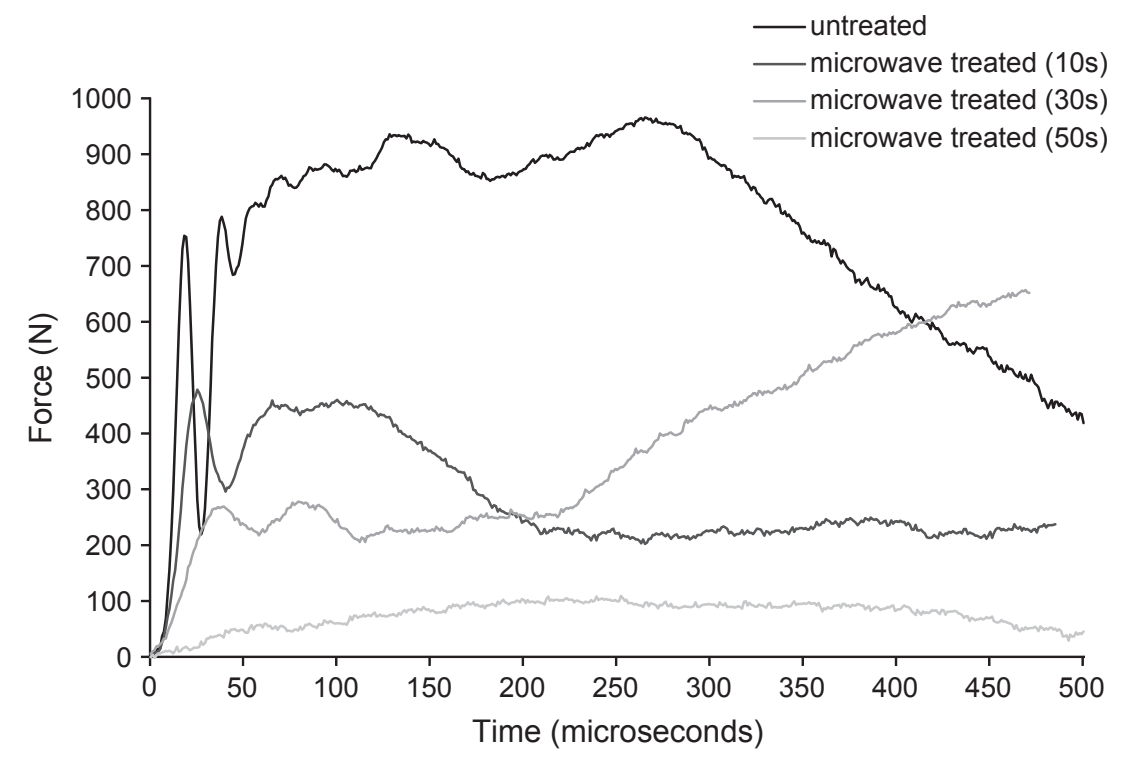

Fig. 7. Example of force-time data for an untreated $10 \mathrm{~mm}$ concrete particle ( $40 \mathrm{~mm}$ bearing ball; $100 \mathrm{~mm}$ drop height).

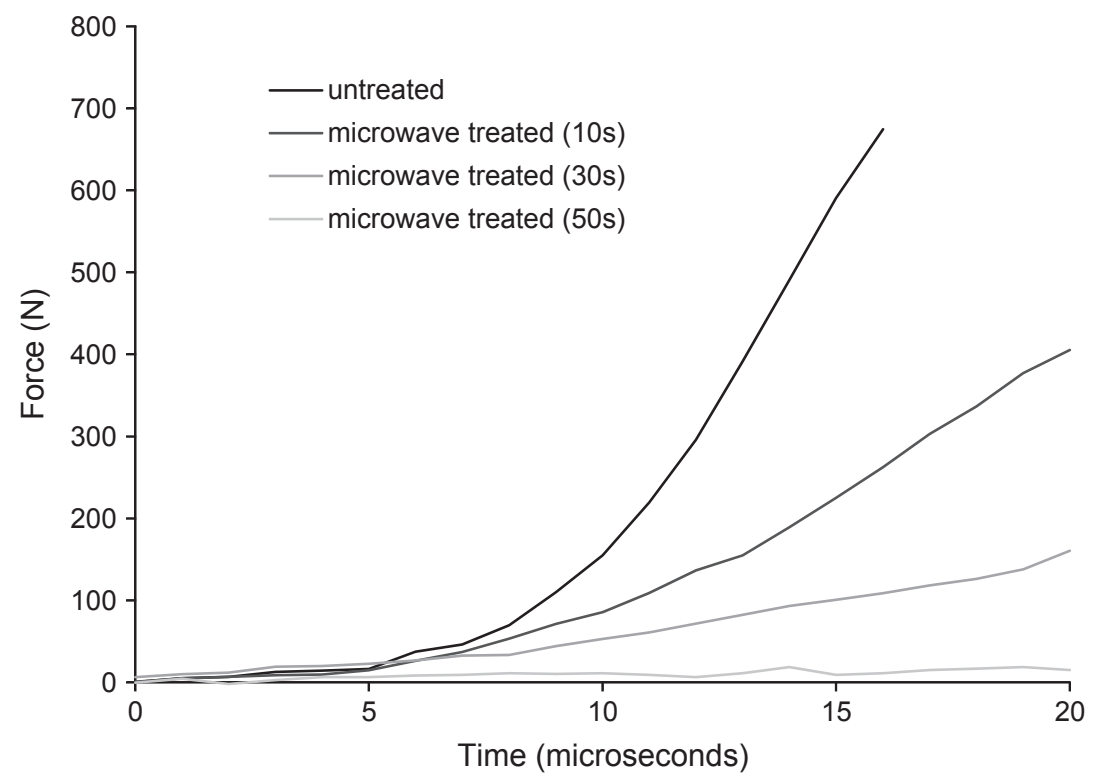

Fig. 8. Direct measure of concrete embrittlement increase with microwave exposure time. Decreasing slope of force-time curve is a direct evidence of the reduction of concrete's modulus of elasticity.

\subsection{Fragmentation of concrete particles and liberation of constituents}

Fig. 10 gives the fragment size distributions obtained with both untreated and treated concrete particles after Hopkinson bar impact testing. Impact tests were carried out with a $40 \mathrm{~mm}$ ( $260 \mathrm{~g}$ ) bearing ball dropped from $100 \mathrm{~mm}$. Fragmentation of untreated concrete generated large particles, $83 \mathrm{wt} \%$ of the fragments having a size coarser ( $\geqslant 2.8 \mathrm{~mm}$ ) than the largest aggregate particles. In fact, untreated particles mainly yielded fragments larger than $5 \mathrm{~mm}$, which correspond to the $10 \mathrm{~mm}$ concrete particle being split in two nearly equal halves during impact. In contrast, only $14 \mathrm{wt} \%$ of concrete fragments from 50s tests are larger than the largest aggregate particles. The fineness of the fragments obtained with the concrete particles treated for $50 \mathrm{~s}$ is significantly greater than that obtained with the untreated particles. Concrete treated for $10 \mathrm{~s}$ and $30 \mathrm{~s}$ demonstrate an intermediate fragment size but the rate of change is not constant. The increasing fineness of the fragment size distribution adds to the earlier observations about the dramatic change in fracture properties with microwave exposure time. It permits conclusion that the microwave process produces extensive microstructural damage, creating significant amounts of new surface area, which results in a strong change in comminution behaviour of the concrete.

Liberation is measured by the aggregate and cement distributions after acid dissolution and can be seen in Figs. 11 and 12. Fig. 11 shows that nearly $80 \%$ of the aggregates remain embedded in the $+5 \mathrm{~mm}$ fragment size fraction for untreated particles, which reflects the near absence of liberation of the aggregate phase. In contrast, the $50 \mathrm{~s}$ treated particles exhibit a size distribution that is close to that of the aggregates. Similarly, Fig. 12 gives the amount of cement on a size-by-size basis after impact testing on the Hopkinson bar. What can be seen here is that the longer exposure time produces a very large amount of fine cement particles, with nearly $50 \mathrm{wt} \%$ finer than $1.8 \mathrm{~mm}$. 


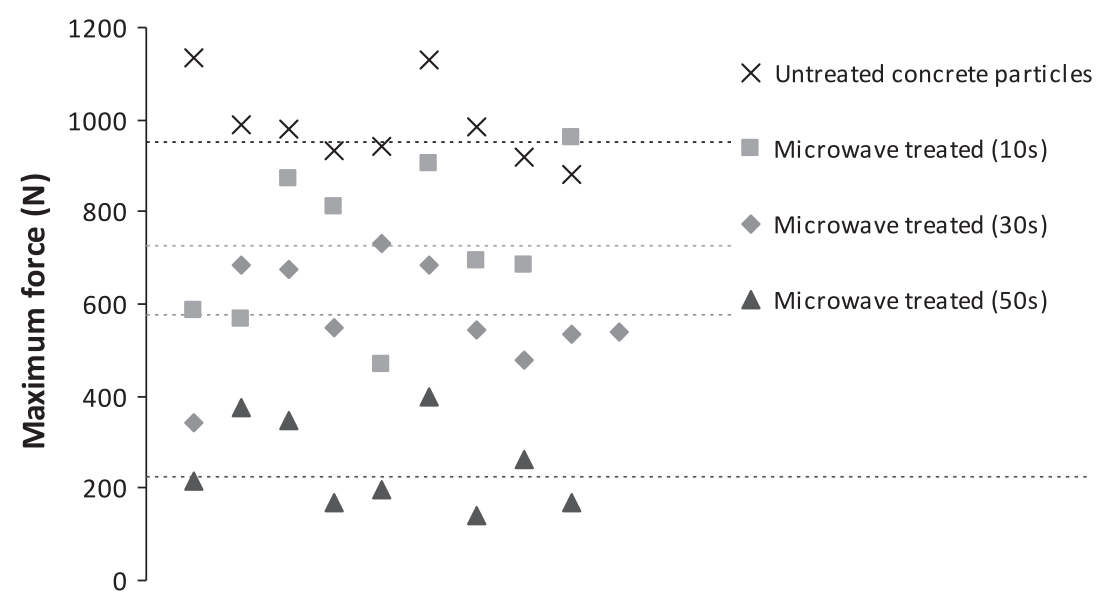

Fig. 9. Maximum force measured with Hopkinson bar with untreated and treated $10 \mathrm{~mm}$ concrete particles (40 mm bearing ball; $100 \mathrm{~mm}$ drop height).

Table 2

Mean fracture properties measured with the fast Hopkinson bar for $10 \mathrm{~mm}$ concrete particles, with and without microwave treatment (N.B.: With 50 s exposure, values of energyat-first-fracture and particle strength are not representative of the average behaviour of corresponding particles as only very few particles yielded distinct fracture events).

\begin{tabular}{lll}
\hline & Maximum force $(\mathrm{N})$ & Energy-at-first-fracture $(\mathrm{mJ} / \mathrm{g})$ \\
\hline Untreated concrete particles & $948(\min : 538, \max : 1423)$ & $2.7(\min : 1.7, \max : 4.4)$ \\
Treated particle $(10 \mathrm{~s})$ & $727(\min : 468, \max : 1156)$ & $2.7(\min : 0.8, \max : 3.4)$ \\
Treated particle $(30 \mathrm{~s})$ & $573(\min : 334, \max : 1150)$ & $4.1(\min : 2.3, \max : 11)$ \\
Treated particle $(50 \mathrm{~s})$ & $226(\min : 100, \max : 644)$ & $1(\min : 0.4, \max : 2)$ \\
\hline
\end{tabular}



Fig. 10. Fragment size distribution from single-particle impact tests with untreated and treated $10 \mathrm{~mm}$ concrete particles (40 mm bearing ball; $100 \mathrm{~mm}$ drop height).

Although one may argue that the fine cement fragments were produced by the impact, it is more likely that the microwaves were responsible for shattering the continuous cement phase throughout the concrete particle volume. Such a reasoning would tend to indicate that the microwave process is not as selective as originally thought in that it does not target aggregate-cement grain boundaries specifically, otherwise cement fragments would be expected not to be so drastically shifted towards the fine particle size classes. This is supported by the minimal similarity between the aggregate distribution in the concrete and that in the concrete treated for $10 \mathrm{~s}$ and $30 \mathrm{~s}$. From such limited data, and without looking at the texture of fragments after fracture, it is premature however to make a conclusion regarding the selectivity of microwave induced fracture of concrete.

The overall aggregate liberation is plotted in Fig. 13. There seems to be a small gain in aggregate liberation from $10 \mathrm{~s}$ to $30 \mathrm{~s}$ exposure time, however the gain is significant between $30 \mathrm{~s}$ and $50 \mathrm{~s}$. The nature of this change is unknown at this stage; however it is clear that this change is targeting some of the phases that are present at the interface between aggregates and cement paste due to the large increase in liberation. Untreated concrete particles did yield very low aggregate liberation, with a value of $3.4 \%$. Liberation is therefore found to increase with exposure time; however the increase is not linear. After an exposure of $50 \mathrm{~s}$ approximately $60 \%$ of the aggregate particles were liberated after impact. The greatest increase in liberation occurred between the $30 \mathrm{~s}$ and $50 \mathrm{~s}$ exposure time, which echoes the change in fragmentation behaviour discussed earlier between these exposure times.

\subsection{Combining microwave and impact comminution}

As indicated earlier in the paper, the single-particle approach was implemented as it permits investigation of individual processes, for which energy absorption can be quantified in principle. Adding to the energy absorbed by single particles during microwave tests, which was discussed in Section 3.2., the fast Hopkinson 


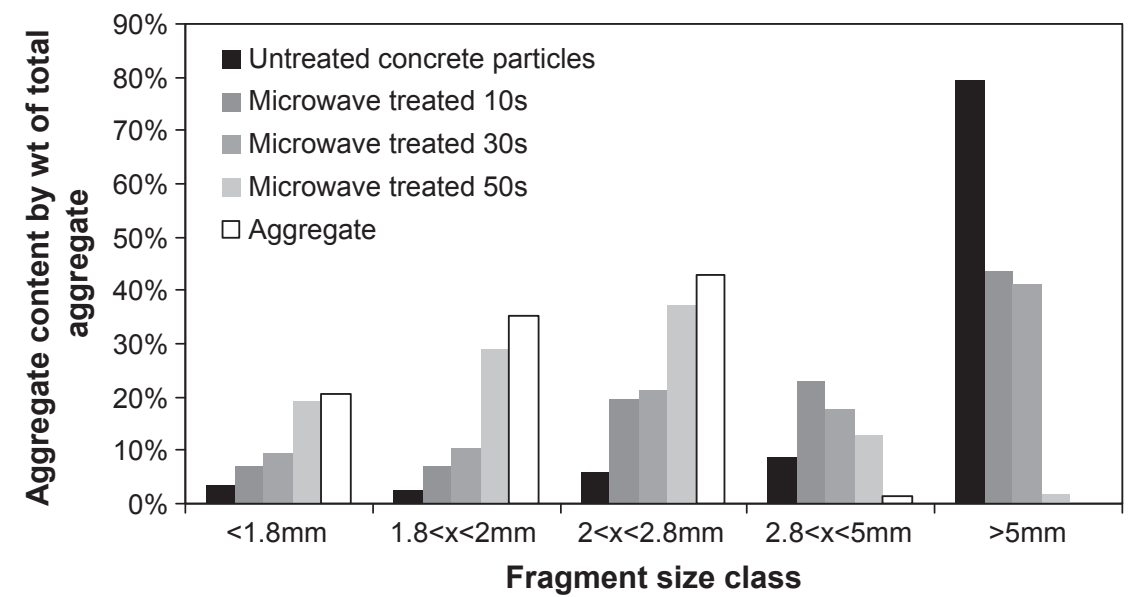

Fig. 11. Comparison of aggregate distribution between microwave treated and untreated $10 \mathrm{~mm}$ concrete particles after single-particle impact testing.

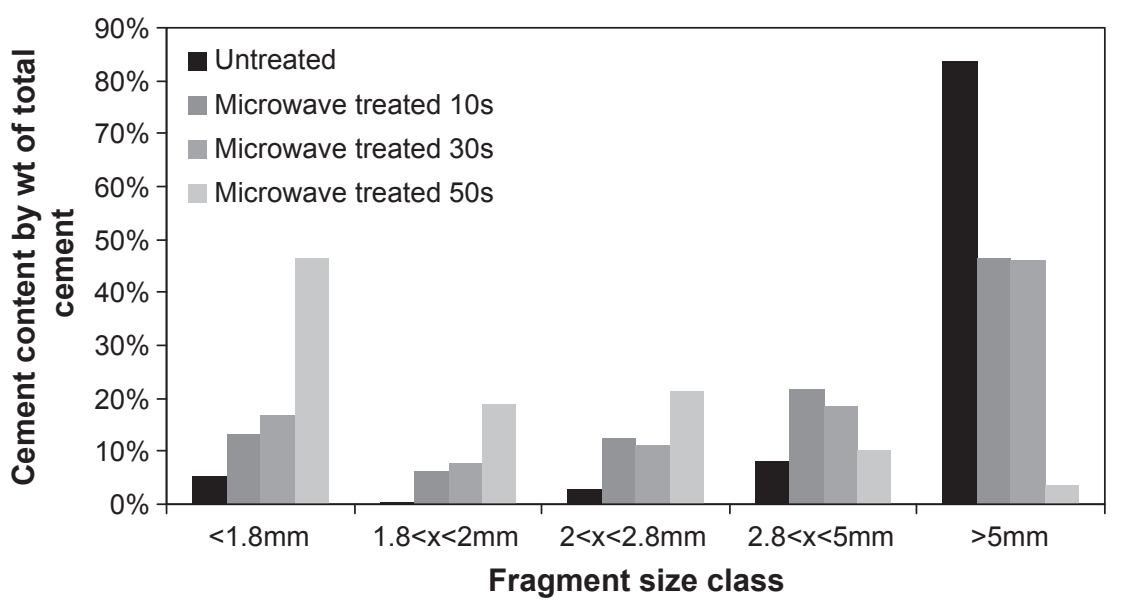

Fig. 12. Comparison of cement distribution between microwave treated and untreated $10 \mathrm{~mm}$ concrete particles after single-particles testing.

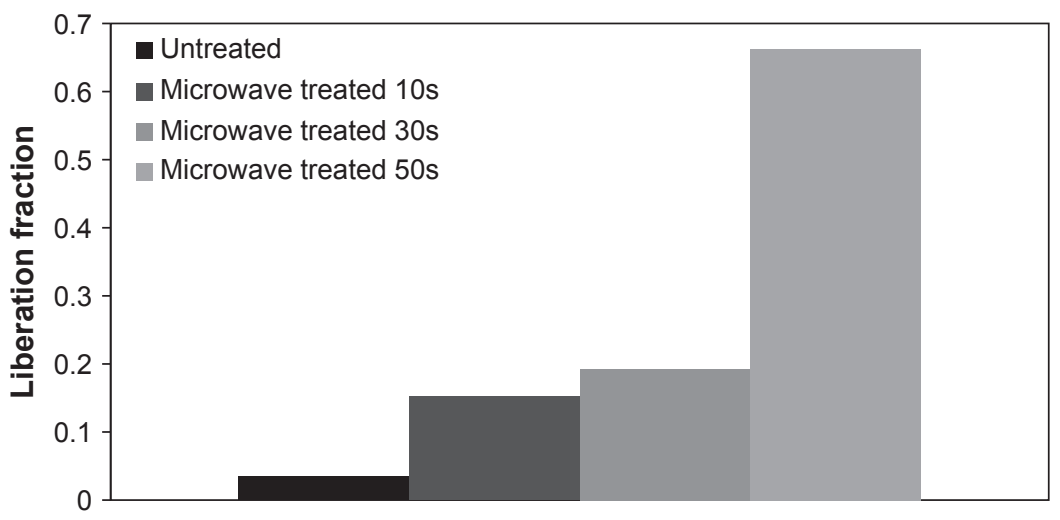

Fig. 13. Liberation of the aggregate phase.

bar yields measurement of the energy actually absorbed by the particle during impact tests. The impact conditions used here corresponded to $31 \mathrm{kWh} / \mathrm{t}$. The fraction of impact energy absorbed by concrete particles decreased from close to $100 \%$ of the impact energy for untreated concrete to close to $55 \%$ for concrete treated for 50 s.

The energy absorbed during microwave treatment plus impact fracture can therefore be added for every particle, such that the overall energy absorption can be quantified. Fig. 14 then shows the aggregate liberation as a function of the average energy absorbed by concrete particles during microwave and comminution tests, under the test conditions used in this work.

The balance of energy absorption changes with the length of microwave exposure, but in any case both microwave and size reduction processes both make significant energy contributions. Optimisation of the proposed process, which includes microwave 


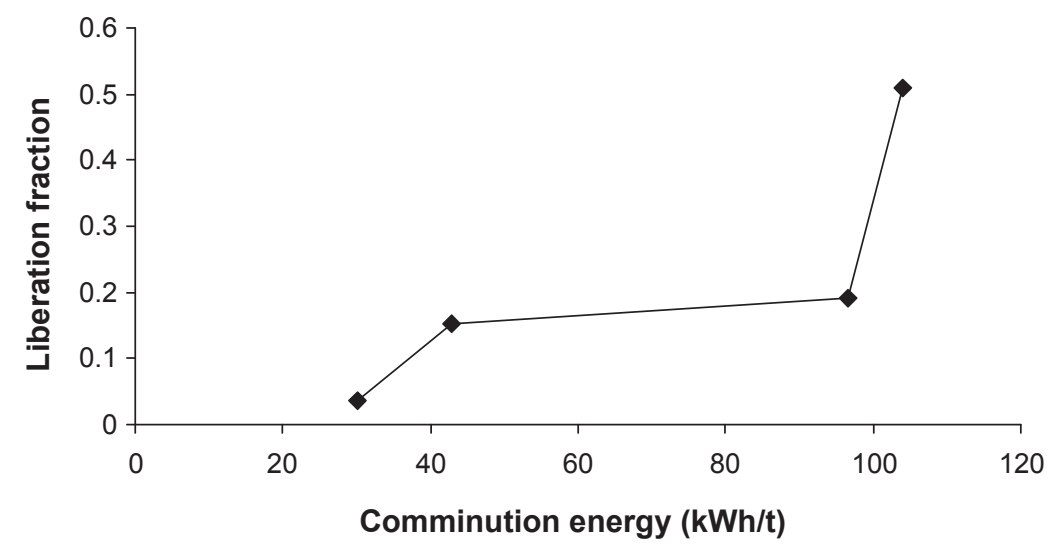

Fig. 14. Measured aggregate liberation as a function of the overall microwave and comminution energy.

heating followed by comminution, will come down first to an optimum end state for the material, whether or not the cement phase is to be recycled and how fine the fragments should be, then an optimum balance between physical and microwave processes before an optimisation of each process individually. As indicated earlier, due to the low power test rig that was used here, the energy consumption obtained is probably significantly higher than what could be obtained with high power microwave systems, say $30 \mathrm{~kW}$ or more. It is also important to note that the size distribution of the aggregates, as found in Fig. 11 is left unchanged, which is quite a valuable observation for the purpose of recycling.

\section{Discussion}

The nature of the changes in mechanical, comminution and liberation properties of concrete subjected to microwaves is largely unknown. The mechanisms behind such changes, which can be so profound as to remove all traces of elastic-brittle behaviour in concrete, are definitely related to modifications of specific mineral phases inside the cement matrix, in the bulk of the matrix as well as along aggregate-cement paste grain boundaries. More research is required to elucidate the nature of these changes, whose understanding is probably the key to finding the best conditions for applying microwaves to concrete with the aim of enhancing liberation of the phases with minimum energy consumption. As discussed earlier in this paper, one pivotal issue in understanding this process revolves around mapping the spatial distribution of phases inside concrete and measuring their properties at the molecular scale at which microwaves affect matter. From a process perspective, properties of the microwaves applied such as power, frequency, exposure time and application mode (pulse frequency) should also be investigated to improve the concrete liberation process.

The liberation of cement was not directly measured here. This would be an interesting addition to this work; however the method used to measure the liberation of aggregate dissolves the cement making this impossible. Cement liberation should therefore be investigated by image analysis techniques.

Besides the issues investigated in the paper, the proposed process raises many engineering related questions.

One engineering issue not addressed here is the separation of the aggregate and cement phases after the comminution step. If the intention is to also recycle the cement, the fact that microwaves pulverise the cement phase, leaving the aggregate particles unaltered seems to be of great value. Indeed, already powderised cement phase would be of value for recycling into the clinker making process, but it would also simplify the process of aggregate and cement separation, which would require only a simple screening step. Gravimetric separation, as suggested by Tomas et al. (2000) would probably be ineffective here, as the density of the aggregate and cement matrix are similar after microwave heating, approximately $2.7 \mathrm{~g} / \mathrm{cm}^{3}$ for the former and $2.3 \mathrm{~g} / \mathrm{cm}^{3}$ for the latter.

Another process parameter that has not been addressed here is increasing process efficiency by making use of the high temperature of concrete immediately after microwave treatment. One option is to increase embrittlement by quenching (Akbarnezhad et al., 2011). Another option could be to perform physical comminution at this elevated temperature. This is a subject for future work.

A third issue is that presented by steel reinforcement. Even assuming the steel and concrete is separated small amounts of ferric debris will remain in the concrete material. The debris could act as an 'initiator,' rapidly increasing the temperature of the material and leading to an overall increase of process efficiency. It could also pose a hazard to equipment, but this is beyond the scope of this project.

As previously stated significantly more powerful machines than those used in this work would be adapted to adopt this technology on an industrial scale (Ali and Bradshaw, 2009). This could be a simple continuous microwave/conveyor system. One could also imagine mobile systems that separate cement and aggregate onsite, which would revolutionise the demolition of concrete structures. This of course raises more engineering questions and is beyond the scope of this work.

\section{Conclusions}

Overall, test results show that concrete particles are severely damaged by exposure to microwaves, the greater the exposure time under the conditions tested in this work, the greater the damage. Concrete particles could be so damaged by microwave treatment that fracture behaviour of the treated concrete showed no resemblance with that of regular, untreated concrete.

Microwave treated particles showed improved comminution properties and liberation of both aggregate and cement phases after impact fracture, both increasing monotonically with duration of exposure to microwaves. As much as $60 \%$ liberation was obtained with $50 \mathrm{~s}$ exposure, as compared with less than $3.5 \%$ for untreated concrete. The effect of microwaves was most severe between 30 and $50 \mathrm{~s}$ exposure times; however the mechanisms responsible for the observed changes require additional research.

Under the test conditions used here, a comminution step is required to harvest the benefits of the severe damage induced by the microwaves, as particles remain largely as particles after microwave heating. Both the microwave heating and comminution processes contribute to the overall energy consumption of the proposed process. The process produces fine cement particles, 
and does not appear to alter the aggregate particles; hence separation of the phases after processing does not appear to be a problem.

Future single-particle test work will be concerned with quantification of the process governing parameters, with the aim of optimisation on the basis of net energy consumption and degree of liberation. The key addition to the single-particle testing protocol presented in this paper will be microscopic investigation of sectioned cement after microwave treatment to reveal microscopic changes that occur within the concrete during exposure to microwaves, particularly fracture growth. Understanding the link between concrete microstructure, particularly the influence of the ITZ and selective embrittlement and liberation by microwaves is clearly a pivotal point for development of this process.

\section{Acknowledgments}

This research work is being conducted as part of the COFRAGE project, which is funded by the Agence Nationale pour la Recherche (the French National Research Agency) through the ECOTECH program. The authors would like to thank their partners from the laboratoire de l'Intégration du Matériaux au Système (IMS) for the work on the dielectric characterisation of concrete components (Table 1).

\section{References}

Akbarnezhad, A., Ong, K.C.G., Zhang, M.H., Tam, C.T., Foo, T.W.J., 2011. Microwaveassisted beneficiation of recycled concrete aggregates. Construction and Building Materials.

Ali, A.Y., 2010. Understanding the effects of mineralogy, ore texture and microwave power delivery on microwave treatment of ores, PhD dissertation. University of Stellenbosch.

Ali, A.Y., Bradshaw, S.M., 2009. Quantifying damage around grain boundaries in microwave treated ores. Chemical Engineering and Processing 48, 1566-1573.

Amankwah, R.K., Ofori-Sarpong, G., 2011. Microwave heating of gold ores for enhanced grindability and cyanide amenability. Minerals Engineering 24, 541544.

Bourgeois, F., Banini, G., 2002. A portable load cell for in-situ ore impact breakage testing. International Journal of Mineral Processing 6, 31-54.

Constantinides, G., Ulm, F.J., 2004. The effects of two types of c-s-h on the elasticity of cement-based materials: results from nanoindentation and micromechanical modeling. Cement and Concrete Research 34, 1293-1309.

Costes, J.R., Majcherczyk, C., Binkhorst, I.P., 2010. Total recycling of concrete. Commissariat à l'Énergie Atomique.

Figg, J., 1974. Microwave heating in concrete analysis. Journal of Applied Chemistry and Biotechnology 24, 143-155.

Klee, H., 2009. Recycling concrete. The Cement Sustainability Initiative. The World Business Council for Sustainable Development.

Galbenis, C.T., Tsimas, S., 2006. Use of construction and demolition wastes as raw materials in cement clinker production. China Particuology 4, 83-85.

Gottlieb, P., Wilkie, G., Sutherland, D., Ho-Tun, E., Suthers, S., Perera, K., Jenkins, B., Spencer, S., Butcher, A., Rayner, A., 2000. Using quantitative electron microscopy for process mineralogy applications. Journal of the Minerals, Metals and materials Society $52,24-25$.
Gu, Y., 2003. Automated scanning electron microscope based mineral liberation analysis; an introduction to jkmrc/fei mineral liberation analyser. Minerals and Materials Characterization and Engineering 2, 33-41.

Kiss, L., Schönert, K., 1980. Liberation of two component material by single particle compression and impact crushing. Aufbereitungs-technik 5, 223-230.

Fischer, C., Davidsen, C., 2010. Europe as a recycling society, the European recycling map. European Environment Agency.

Knight, R., Abad, A., 1995. Rock/water interaction in dieletric properties: experiments with hydrophobic sandstones. Geophysics 60, 431-436.

Kumar, P., Sahoo, B.K., De, S., Kar, D.D., Chakraborty, S., Meikap, B.C., 2010. Iron ore grindability improvement by microwave pre-treatment. Journal of Industrial and Engineering Chemistry 16, 805-812.

Lee, J., Xi, Y., William, K., Jung, Y., 2009. A multiscale model for modulus of elasticity of concrete at high temperatures. Cement and Concrete Research 39, 754-762.

Malesev, M., Radonjanin, V., Marinkovic, S., 2010. Recycled concrete as aggregate for structural concrete production. Sustainability 2, 1204-1225.

Marland, S., Han, B., Rowson, N.A., Merchant, A.J., 1998. Microwave embrittlement and desulpurisation of coal. Acta Montanistica Slovaca 3, 351-355.

Martinez, A., Byrnes, A.P., 2001. Modeling dieletric-constant values of geologic materials: an aid to ground-penetrating radar data collection and interpretation. Kansas Geological Survey.

Metaxas, A.C., Meredith, R.J., 1988. Industrial Microwave Heating. Institute of Engineering and Technology, London.

Nawy, E.G. (Ed.), 2008. Concrete Construction and Engineering, second ed. CRC Press: Taylor and Francis Group.

Pokkuluri, K., 1998. Effect of admixtures, chlorides and moisture on the dieletric properties of portland cement concrete in the low microwave frequency range, Masters thesis. Virginia Polytechnic Institute.

Roy, D.M., Grutzeck, M.W., Shi, D., Lui G., 1993. Cement paste aggregate interface microstructure, Pensylvania State University, Strategic Highway Research Program of the National Research Council.

Schärli, U., Rybach, L., 2001. Determination of specific heat capacity on rock fragments. Geothermics 30, 93-110.

Scrivener, K.L., Crumbie, A.K., Laugesen, P., 2004. The interfacial transition zone (ITZ) between cement paste and aggregate concrete. Interface Science 12, 411421.

Soutsos, M.N., Tang, K., Millard, S.G., 2010. Concrete building blocks made with recycled demolition aggregate. Construction and Building Materials 25, 726735.

Tam, V.W.Y., Tam, C.M., 2006. A review on the viable technology for construction waste recycling. Resources, Conservation and Recycling 47, 209-221.

Tam, V.W.Y., Tam, C.M., Wang, Y., 2007. Optimization on proportion for recycled aggregate in concrete using two-stage mixing approach. Construction and Building Materials 21, 1928-1939.

Tavares, L.M., King, R.P., 1998. Single-particle fracture under impact loading. International Journal of Mineral Processing 54, 1-28.

Tomas, J., Schreier, M., Gröger, T., 2000. Liberation and separation of valuables from building material waste. Chemical Engineering and Technology 23, 809-814.

Ulaby, F.T., Bengal, T.H., Dobson, M.C., East, J.R., Garvin, J.B., Evans, D.L., 1990. Microwave dieletric properties of rocks. IEEE Transactions on Geoscience and Remote Sensing 28, 325-336.

Vorster, W., Rowson, N.A., Kingman, S.W., 2001. The effect of microwave radiation upon the processing of neves corvo copper ore. International Journal of Mineral Processing 63, 29-44.

Walker, R., 2011. Density of bulk materials. 〈http://www.simetric.co.uk $\rangle, 1998-$ 2011.

Youtcheff, J., 2011. Thermal coefficient of portland cement concrete. 〈http:// www.fhwa.dot.gov $\rangle, 2011$.

http://www.engineeringtoolbox.com, 2005-2011. 